\title{
REPRESENTAÇÕES SOBRE CIDADANIA, \\ PARTICIPAÇÃO E SEXUALIDADE: EXPLORANDO O ORKUT
}

\author{
REPRESENTATIONS ON CITIZENSHIP, PARTICIPATION \\ AND SEXUALITY: EXPLORING THE ORKUT
}

Shayana Busson

\begin{abstract}
Resumo
Este trabalho tratou de garimpar algumas comunidades virtuais da aplicação orkut, na rede da internet, relacionadas à temática sexualidade e seus derivados. Buscou-se identificar e discutir as principais maneiras de mobilizações e representações ligadas à sexualidade que a juventude "orkutiana" brasileira tem debatido pela internet. Nossa pesquisa, feita em 10 e 11 de maio de 2008 e 27 de junho de 2009 encontrou 4.487 comunidades virtuais, com no mínimo 3 integrantes, que expressam interesses com os temas: machismo, feminismo, direitos sexuais, gays, lésbicas, aborto, sexo, sexual, gênero, GLBTT e violência contra mulher. Conforme o encontrado, analisamos processos participativos emancipatórios, identitários, de defesa dos direitos sexuais da juventude, entre outros.
\end{abstract}

Palavras-chave: Cidadania Sexual; Orkut; Juventude.

\begin{abstract}
This study explored some virtual communities on Orkut about issues related to sexuality. We discussed representations on sexuality taking into account the youth that deals with Orkut in Brazil. Our research on this social networking website took place on May 10 and 11, 2008 and June 27, 2009. It found 4487 virtual communities, with at least 3 members, expressing concern for topics such as: sexism, feminism, sexual rights, gays, lesbians, abortion, sex, sexual, gender, and violence against women. The content of such topics were analyzed with emphasis on the search of liberation, identity, and sexual rights.
\end{abstract}

Keywords: Sexuality, Sexual issues, Orkut, Youth. 


\section{Introdução}

Neste artigo se analisa a comunicação via realidade da aplicação virtual denominada orkut, sobre temas ligados à cidadania sexual, partindo da premissa de que essas são formas de ciberpolítica que vêm atraindo jovens e têm características singulares quer em comparação com outras formas de participação, quer pelo seu conteúdo, expressando percepções e projetos, em particular dos jovens, que configuram um tipo contemporâneo de cidadania no Brasil.

$\mathrm{Na}$ primeira parte, considerando literatura sobre o tema, discute-se o significado da internet na construção e na ampliação da cidadania e da democracia brasileira, ponderando questões históricas de participação política, cidadania e comportamento político da juventude.

Já na segunda parte demonstra-se exemplos de atuação política de jovens no orkut, relacionada à questões de sexualidade, seus conteúdos, nexos e especificidades. Em suma, este trabalho tenta explanar os encaixes, premissas e eficiências da atuação e participação política da juventude por meio do orkut, no que concernem as opiniões e descrições de sexualidade, a partir do método de pesquisa direta, construção de tabelas resultantes de pesquisa direta, construção de gráficos, análise de dados estatísticos e bibliográficos.

Considera-se que uma das fortes expressões de várias juventudes atualmente tem sido a comunicação via internet, fala-se até de certa onipresença da internet na vida de alguns jovens (RUIZ; RíO, 2008), assim, através da internet, é possível verificar tendências e representações sociais, principalmente por meio de aplicações em que o usuário tem a chance de expressar pública e livremente seu pensamento. Dados estatísticos comprovam tal afirmativa demonstrando que com maior probabilidade os mais jovens usam mais a internet: entre os de 10 a 14 anos, em nível de Brasil, a proporção de internautas é de $24,4 \%$. Entre os de 15 a 17 anos, $34 \%$, entre os de 18 a 19 anos, $32,9 \%$, entre os de 20 a 24 anos, $31,1 \%$; 
entre os de 25 a 29 anos, 27,1\%, entre os de 30 a 39 anos, 21,3\% e a partir dessa faixa etária proporções bem menores são encontradas em relação a uso da internet (PNAD 2005) ${ }^{1}$.

Pesquisas sobre o acesso à internet no Brasil $^{2}$ também comprovam que há uma associação entre renda mensal domiciliar per capita e uso da internet cerca de $27 \%$ das pessoas entre 1 a 2 salários mínimos de renda mensal domiciliar per capita utilizaram a internet nos três últimos meses antes da pesquisa do PNAD 2005, já entre os com rendimento entre $1 / 4$ a $1 / 2$ salários mínimos, a proporção encontrada foi de 15,1\%. Mais alta proporção entre esses estaria na faixa de 5 salários mínimos ou mais de renda mensal domiciliar per capita (PNAD 2005) ${ }^{3}$. Mas, na pesquisa feita pela consultoria em gestão TGI BRASIL a penetração da internet na classe $C$ chegará, em dezembro de 2009, a 45\%, o que nas classes $A$ e $B$ já chegou a $76 \%$. Em termos de acesso global, pela projeção do $\mathrm{IAB}^{4}$, o Brasil deve chegar a cerca de 68,5 milhões de pessoas na internet até o fevereiro de 2010.

Diante desse contexto estatístico brasileiro, onde a maior proporção de acesso à internet é de jovens, de maioria classe A e B, mas já com forte presença da classe C e D, buscamos analisar as principais abordagens juvenis sobre a temática sexualidade, a partir do orkut, visto que tal aplicação da $w e b^{5}$, filiada à empresa Google e criada em $\underline{24}$ de Janeiro de $\underline{2004}$, é a rede social possivelmentre com maior participação de jovens ${ }^{6}$,

\footnotetext{
${ }^{1}$ Pesquisa Nacional por Amostra de Domicílios /IBGE 2005.

Disponível em : http://www.ibge.gov.br/home/estatistica/populacao/acessoainternet/default.shtm Acessado em: 10 de março de 2008.

2 "No total da população de 10 anos ou mais de idade, verificou-se que $21,0 \%$ das pessoas acessaram a internet em algum local (domicílio, local de trabalho, estabelecimento de ensino, centro público de acesso gratuito ou pago, domicilio de outras pessoas ou qualquer outro local), por meio de microcomputador, pelo menos uma vez, no período de referência dos últimos três meses, em 2005". Disponível em: http://www.ibge.gov.br/home/estatistica/populacao/acessoainternet/comentarios.pdf. Acessado em: 02 de julho de 2009.

${ }^{3}$ Vigência de 01.05 .2005 à 01.04 .2006 o salário mínimo tinha o valor de $R \$ 300,00$.

${ }^{4}$ Interactive Advertising Bureau Brasil.

${ }^{5}$ Web é uma palavra inglesa e quer dizer rede e/ou teia, usada comumente para designar o ambiente da internet

${ }^{6}$ A Google informa que $54,66 \%$ de seus usuários são da faixa etária de 18 à 25 anos. E $13,55 \%$ declaram-se de 26 à 30 anos. Disponível em: http://www.orkut.com.br/Main\#MembersAll.aspx. Acessado em: 20 de julho de 2009.
} 
apresentando mais de 23 milhões de usuários no Brasil $^{7}$, além disso, essa aplicação tem uma configuração mais pública, existindo total possibilidade do usuário expressar e divulgar livremente sua opinião, seja por meio de scraps $^{8}$ ou por meio da criação de comunidades virtuais. Para a visualização e/ou divulgação das opiniões e comunidades basta que o indivíduo crie endereço e senha de acesso, tudo gratuitamente. Um outro ponto do nosso interesse no orkut enquanto fonte de análise, é o fato de que as comunidades virtuais não são criadas pelos administradores do orkut e sim pelos próprios usuários, onde o único critério imposto é que estas comunidades não sejam baseadas em temas e propostas de cunho ilícito, o que muitas vezes é burlado pelos internautas.

Nesse sentido "orkutiano" de uma maior abertura para a livre expressão dos jovens, verificamos concomitantemente que "há na sociedade brasileira atual uma ênfase significativa na construção de uma nova cidadania" (DAGNINO, 2002, p.10). Assim é que alguns autores chegam a asseverar que a internet sem dúvida tem contribuído para esse panorama cidadão, justamente por funcionar como uma espécie de "conversação civil" ilimitada (MARQUES, 2006), construindo redes de solidariedade, deflagrando movimentos políticos, questionando direitos, etc.

O retorno às instituições básicas da democracia no Brasil a partir da década de 80 não foi suficiente para acabar com o problema das desigualdades nas suas várias expressões- de renda, racial, de gênero, geração etc, deste modo, setores de movimentos sociais, acadêmicos, filantropos e ativistas aguçaram suas bandeiras em torno de novas necessidades, quais sejam: aprofundar o controle do Estado por parte da sociedade, bem como alavancar o reconhecimento dos sujeitos enquanto portadores de direitos. $\mathrm{O}$ que na década de 60 , entre os setores politicamente ativos, se configurava numa luta política contra o Estado ditatorial em busca de alternativas para o

\footnotetext{
${ }^{7}$ A Google informa que $49,67 \%$ de todos os usuários do orkut são brasileiros. Em segundo lugar está os Estados Unidos com 20,47! E terceiro lugar a Índia, com 18,09\%. Disponível em: http://www.orkut.com.br/Main\#MembersAll.aspx. Acessado em: 20 de julho de 2009.

${ }^{8}$ Scraps é uma palavra da língua inglesa e quer dizer recados.
} 
sistema capitalista, se transformou, nas décadas seguintes e com o fim do regime militar numa "postura de negociação que aposta na possibilidade de uma atuação conjunta, expressa paradigmaticamente na bandeira da participação da sociedade civil" "(DAGNINO, 2002, p.13). É, portanto, nesse contexto de evidência de um novo paradigma político que se inscreve a importância de examinar a internet, entendida por muitos especialistas, como esfera pública, fonte de debates coletivamente compartilhados, e articulações sociais. De acordo com Manuel Castells (1999) as transformações da política e dos processos democráticos na sociedade contemporânea têm como principal fator responsável o uso de novas tecnologias da informação.

Compreendendo sinteticamente, dizemos que a consolidação do ideal de cidadania no Brasil (defesa dos direitos e diminuição das desigualdades) se projetou na construção cada vez mais ampla de uma democracia que assegurasse à sociedade civil a participação ora na co-gestão com o Estado, ora na promoção do debate no interior da sociedade. Nessas circunstâncias o livro Sociedade civil e espaços públicos no Brasil, organizado pela autora Evelina Dagnino (2002), propõem o exame dos diversos e recentes espaços públicos brasileiros, fazendo alusão ao orçamento participativo, às ongs, conselhos gestores, fóruns temáticos e à movimentos sociais, mas não faz nenhuma referência à internet enquanto formato complementar de um espaço público no Brasil. Já outros cientistas e pesquisadores acreditam que a introdução de uma nova infra-estrutura tecnológica fez ressurgir fortemente as esperanças democráticas de participação no país. (SORJ, 2006; VAZ, 2003; GOMES, 2005)

Aliás, na literatura atual que relaciona comunicação e ciências sociais muitos debates têm versado em como as ferramentas e dispositivos eletrônicos implementam um novo modelo de participação e democracia política. Assim, se discute que as oportunidades de participação via web são as mais diversas e tanto podem partir da esfera estatal através de: plebiscito eletrônico, governo eletrônico, portais que possibilitam transparência do 
Estado, etc, quanto da esfera civil, através de: cibermilitância e novos movimentos sociais (GOMES, 2005)

Partindo desses princípios de possibilidades de participação política na internet este trabalho tenta demonstrar a atuação virtual da juventude em relação à cidadania sexual. Por exemplo, durante o curso da pesquisa notamos que entre os jovens que interagem no orkut há um proeminente interesse sobre sexualidade no que concerne à exigência de direitos sexuais como: anti-homofobia, casamento de pessoas do mesmo sexo, adoção de pais homossexuais, troca de sexo, identidade de gênero, discriminação por orientação sexual, direitos reprodutivos, direito ao matrimônio. Existe, portanto, uma correspondência de idéias entre o que jovens internautas têm declarado e o que se prescreve idealmente na Declaração de Direitos Sexuais ${ }^{9}$.

Ao contrário do que tem se disseminado sobre uma recente juventude sem orientação política, sem ideais e sem perspectivas quanto aos seus direitos, a rede virtual enquanto representativa de idéias de algumas juventudes demonstra ampla disposição dos usuários para tratarem de assuntos ligados à direitos sexuais, liberdades sexuais, quebra de estereótipos, entre outros. Bem como, em oposição ao que muitos têm entendido sobre o orkut $^{10}$, enquanto mero incentivador de encontros, paqueras, e grande

\footnotetext{
${ }^{9}$ Segundo a Declaração de Direitos Sexuais de 1997 todo cidadão tem direito a "viver e expressar livremente a sexualidade sem violência, discriminações e imposições e com respeito pleno pelo corpo do (a) parceiro (a). /Direito de escolher o (a) parceiro (a) sexual. /Direito de viver plenamente a sexualidade sem medo, vergonha, culpa e falsas crenças / Direito de viver a sexualidade independentemente de estado civil, idade ou condição física / Direito de escolher se quer ou não quer ter relação sexual / Direito de expressar livremente sua orientação sexual: heterossexualidade, homossexualidade, bissexualidade, entre outras / Direito de ter relação sexual independente da reprodução / Direito ao sexo seguro para prevenção da gravidez indesejada e de DST/HIVIAIDS / Direito a serviços de saúde que garantam privacidade, sigilo e atendimento de qualidade e sem discriminação/ Direito à informação e à educação sexual e reprodutiva".

${ }^{10}$ A própria Google define o Orkut como: "uma comunidade on-line criada para tornar a sua vida social e a de seus amigos mais ativa e estimulante. A rede social do orkut pode ajudá-lo a manter contato com seus amigos atuais por meio de fotos e mensagens, e a conhecer mais pessoas. Com o orkut é fácil conhecer pessoas que tenham os mesmos hobbies e interesses que você, que estejam procurando um relacionamento afetivo ou contatos profissionais. Você também pode criar comunidades on-line ou participar de várias delas para discutir eventos
} 
responsável pela aparição de futilidades juvenis, ele cada vez mais tem sido utilizado como um campo fértil, barato e eficaz para disseminação de ideais políticos e questionamentos sociais no campo sexual.

\section{Análise de dados}

Em um paralelo de observações foram estudados os títulos e descrições de 4.487 comunidades virtuais, com no mínimo 3 integrantes, selecionadas a partir dos recortes: sexualidade, gênero, feminismo, machismo, gays, lésbicas, violência contra mulher, aborto, sexual, sexo, direitos sexuais e LGBTT ${ }^{11}$. Esses recortes foram as palavras-chave criadas arbitrariamente segundo o que entendemos sobre as tendências de abordagens relativas à sexualidade. No orkut há apenas 1 categoria disponível para busca do tema sexualidade, chamada: gays, lésbicas e bi, que foi criada pelos administradores. Assim, compreendemos que analisar somente as comunidades inseridas na categoria gays, lésbicas e bi, seria um tanto restritivo, por isso criamos esse método de busca por palavras-chave.

No Quadro 1 a seguir, nossa coleta de dados sobre o número de comunidades virtuais, segundo recorte de 9 palavras-chave, e as 4 classificações temáticas dessas comunidades, de acordo com o que assimilamos sobre mensagens veiculadas nos títulos e descrições dessas comunidades. As comunidades que trazem o tema do aborto, gays e lésbicas foram discutidas mais adiante, pois não puderam entrar no esquema de classificações que aqui sugerimos.

Quadro 1- Explorando o Orkut - Número de Comunidades Virtuais Segundo 9 Palavras-chave Sugeridas e suas Classificações

atuais, reencontrar antigos amigos da escola ou até mesmo trocar receitas favoritas". Disponivel em: http://www.orkut.com/About.aspx. Acessado em: 02 de julho de 2009.

${ }^{11}$ Lésbicas, Gays, Bissexuais, Travestis e Transsexuais - LGBTT é uma sigla utilizada para identificar todas as orientações sexuais minoritárias e manifestações de identidades de gênero divergentes do sexo designado no nascimento. 


\begin{tabular}{|c|c|c|c|c|c|c|c|c|c|}
\hline \multirow[t]{3}{*}{$\begin{array}{l}\text { Classificação temática das } \\
\text { comunidades } \\
\end{array}$} & & & & & & & & & \\
\hline & Sexualidade & Gênero & Feminismo & Machismo & $\begin{array}{l}\text { Violência } \\
\text { contra } \\
\text { mulher }\end{array}$ & Sexual & Sexo & $\begin{array}{l}\text { Direitos } \\
\text { Sexuais }\end{array}$ & LGBTT \\
\hline & 114 & 44 & 57 & 94 & 81 & 564 & 577 & 3. & 175 \\
\hline $\begin{array}{l}\text { Direitos humanos para } \\
\text { homossexuais } \\
\text { - Liberdades e diversidade } \\
\text { sexual } \\
\text { Quebra de estereótipos } \\
\text { sexuais }\end{array}$ & & & & & & & & & \\
\hline $\begin{array}{l}\text { - Contra exploração sexual } \\
\text { - Contra opressãoe } \\
\text { machismo } \\
\text { - Contra preconceitos } \\
\text { religiosos sexuais }\end{array}$ & 72 & 29 & 45 & 86 & 81 & 177 & 5. & 3. & 141 \\
\hline $\begin{array}{l}\text { - Saúde sexual fisica ou } \\
\text { psicológida } \\
\text { - Prevençã a DST } \\
\text { - Educaçã } ~ s e x u a l \\
\text { - Estudos spbre sexualidade }\end{array}$ & 11 & 1 & - & - & - & 19 & $\&$ & - & - \\
\hline $\begin{array}{l}\text { - Discriminação sexual e de } \\
\text { gênero } \\
\text { - Apelos sexuais agressivos } \\
\text { e/ou apologéticos } \\
\text { - A abusos sexuais. }\end{array}$ & 6. & 1 & 11 & 7. & - & 24 & 2 & - & 3. \\
\hline $\begin{array}{l}\text { - Convite de relação sexual } \\
\text { ou amorosa, } \\
\text { - Fantasias sexuais } \\
\text { - Ironia a sexo de animais, } \\
\text { - Nome de bandas e pessoas } \\
\text { que lembram sexo } \\
\text { - Horóscopo no campo da } \\
\text { sexualidade } \\
\text { - Propaganda de empresas } \\
\text { voltadas ao ramo } \\
\text { - Indicação de vídeos } \\
\text { pomográficos, artistas, } \\
\text { festas } \\
\text { - Culto ao corpo }\end{array}$ & 25 & 13 & 1. & 1 & - & 344 & 562 & - & 31 \\
\hline
\end{tabular}

Fonte; Levantamento no www.orkut.com dias 10 e 11 de maio de 2008 e 27 de junho de 2009.

Considerando o quadro anterior nota-se que o imaginário social de jovens usuários do orkut em relação ao tema sexualidade não está preponderantemente ligado às questões pautadas em preocupações por direitos humanos para homossexuais, liberdades sexuais, quebra de 
estereótipos sexuais, contra a exploração sexual, contra opressão e machismo ou contra preconceitos religioso-sexuais, porém apresenta, de acordo com a classificação temática aqui definida e os índices numéricos, dimensões relevantes. Constatamos que $37,3 \%$ das comunidades pesquisadas refletem interesses por expressar e reforçar opinião pública propositiva ao debate em defesa de direitos sexuais, o que demonstra certo engajamento com bandeiras de minorias sexuais e movimentos politizados. Vale dizer inicialmente que segundo Corrêa (2006) a apreensão dessa temática remete à década de 60 :

\begin{abstract}
O debate intelectual e político que fez da sexualidade um tema político na era contemporânea teve origem na "revolução sexual" dos anos 1960, mas ganhou densidade e legitimidade acadêmica a partir de sua vinculação com as teorias pósmodernas que situam a sexualidade no coração da formação cultural e política moderna. Essa inflexão intelectual posteriormente denominada viragem lingüística - deu grande fôlego político aos movimentos societários que se mobilizam ao redor das questões da sexualidade (Idem, p. 105).
\end{abstract}

Com o achado de 542 comunidades virtuais ligadas à cidadania sexual, se vê que em meados de 2009 a adesão da juventude brasileira à luta por direitos sexuais é significante não só em termos numéricos, pois elas representam $37,3 \%$ do total, como também em termos de conscientização, pois sua expressividade via internet pode estar funcionando como referência na orientação sexual de comportamentos, posições e práticas entre homens e mulheres, transformando cotidianamente valores $\mathrm{e}$ instituições morais (BRAGA, 2008).

Muitas formas de ação coletiva, dentro ou fora de movimentos sociais reconhecidos têm como escopo mudar a ordem social existente, influenciar os resultados de processos políticos que envolvem valores e comportamentos culturais, e com veemência acabam se tornando objeto de inspiração nas decisões institucionais de governo. Mesmo atuando sem legitimação ou permissão institucional, alguns agrupamentos se associam com caracteres revolucionários de transformação social, e gradualmente 
vão se tornando atores sociais importantes para a promoção da cidadania. Vejamos o que diz a comunidade "Contra Ditadura de Gênero":

\section{Quadro 2- Objetivos declarados da comunidade "Contra ditadura de gênero" (206 membros)}

"Faça então o entender que: os pêlos nas axilas das feministas causam mais horror que um estupro."

O que é ser mulher pra você, sacana? É ofuscar dor, redimir pensamentos, fingir orgasmo, converter-se numa cultura machista, rir de piadas infames contra as próprias mulheres, justificar um estupro, não exercer certas atividades, impulsionar teus direitos à teus filhos pela maternidade, unificar o teu cérebro à um ventre, não ter escolhas, sambar

vestir

uma

burca?

O QUE É SER MULHER PARA TI? Teu cérebro se limita à um padrão de estética o qual tu é a porra de uma boneca inflável? E tuas unhas, tu as fez hoje? O que é ser mulher para você, PORRA?

Fonte: $\quad$ http://www.orkut.com.br/Main\#Community.aspx?cmm=29255704.

Pesquisa feita em 20 de julho de 2009.

É consenso que emergem, em nosso dia a dia, diversos movimentos jovens politizados que não mais se resumem a organizações partidárias, sindicatos e grêmios estudantis, bem como as abordagens suscitadas por esses movimentos também não mais se restringem à clássica luta por melhores salários, pelo socialismo, pelo fim de regimes ditatoriais, enfim. Segundo Carrano e Brenner (2008) os jovens de hoje ainda mantêm a motivação para a participação, porém, é um número reduzido que se encontra disposto a fazê-la em espaços tradicionais e institucionalizados [...] (Idem, p. 1), ou seja, novos contextos de participação e novos sentidos de mobilização social têm surgido no Brasil, demonstrando tendências mais autônomas de jovens na criação de seus próprios mecanismos organizacionais políticos. 
Nesse sentido, podemos sugerir que a internet é um desses novos ambientes ora organizativos, ora comunicativos, ora meramente manifestos, que têm canalizado conflitos e antagonismos políticos, seja no campo sexual, seja no campo social, e por isso deve ser considerado também para o estudo das inovações, representações e concepções políticas contemporâneas $^{12}$.

Num outro dado verifica-se que a maioria das comunidades, cerca de $57,1 \%$, foram criadas com temas como: convite de relação sexual e/ou amorosa, fantasias sexuais, culto ao corpo, ironia à sexo de animais, indicação de vídeos pornográficos, etc percebe-se, com isso, uma visão declarada da maioria jovem por certo escracho pornográfico e obscenidades no entendimento sobre sexualidade.

De forma geral é sabido que historicamente a internet nasceu como arma militar, mas quando se difundiu na sociedade já em 1970 nos EUA (BOGO, 2000) passou a ser um dos mais acessados instrumentos de entretenimento pornográfico, e somente depois de anos lhe foi atribuída à viabilidade de divulgação de trabalhos científicos, comerciais, educativos, etc. ${ }^{13}$

\begin{abstract}
A internet tem se tornado um espaço de mercado sexual que de algumas maneiras é o equivalente aos bares gays e aos lugares de flerte, como uma entrada para um 'oasis erótico', assim como a realidade virtual de 'oasis erótico' em si mesma, ela contém muitas características dos espaços tradicionais para contatos homossociais e homossexuais enquanto agrega algumas outras mais (ROSS et al, 2000, p. 750 apud ZAGO, 2009).
\end{abstract}

12 Segundo BRAGA (2008) "em artigo publicado em 1968, intitulado The Computer as a
Communicaton Device, os autores, também fundadores da ARPANET, forneciam as idéias
conceituais para o desenvolvimento da internet: 1) redes de comunicação são mais que enviar
e receber informação de um ponto a outro, os/as agente são participantes ativos/as que têm
papel central no processo comunicativo; 2)comunicação é um processo de reforço mútuo, que
envolve criatividade; 3)o computador digital é um meio flexível, interativo que pode ser utilizado
para a comunicação humana cooperativa; 4) a comunicação baseada em computadores exige
um enquadramento comum da situação."
13 Conforme o Site Boa Saúde "em todo o mundo, os endereços mais visitados são os de sexo.
Segundo pesquisa realizada recentemente pela Sociedade Brasileira de Sexualidade Humana,
20 a $25 \%$ das pessoas que interagem com a internet freqüentam páginas eróticas. Nos Estados
Unidos o número é maior. São nove milhões de freqüentadores, dos quais quatro milhões
podem ser considerados viciados. Dos nove milhões, 8,5\% freqüentam os sites por mais de 11
horas semanais".
Disponivel http://boasaude.uol.com.br/Lib/ShowDoc.cfm?LibDoclD=3994\&ReturnCatID=1784 Acessado em: 20 de agosto de 2009. 
Deste modo, apesar dos esforços educativos e politizados de centenas de militantes/atuantes virtuais, é notável que as temáticas pornográficas, eróticas e de culto ao corpo povoam mais o imaginário da juventude atualmente do que propriamente os temas indicativos de defesa por direitos sexuais.

Porém, na divergência desse nosso espírito "politicamente correto" o autor Felipe Zago acredita que os referenciais de sexualidade como: culto ao corpo, erotismo, pornografia e etc, que aqui classificamos como fora de um contexto de busca pela cidadania sexual são efeitos da visibilidade da homossexualidade experimentada na década de 80 pela mobilização política engendrada pelos movimentos sociais (ZAGO, 2009. p.02). Na mesma linha, para o site Boa Saúde a internet ajudou a democratizar o sexo. [...] É a forma que diz não à repressão do desejo e que alia erotismo com uma pitada de realidade.

Essas declarações por ora então nos fornecem maiores subsídios para compreender como pode funcionar a dinâmica política dos jovens através da internet. Notamos que tal dinâmica tanto pode decorrer da criação de comunidades que explicitamente defendam e fomentam os direitos sexuais, como podem somente representar um estado de declaração dos desejos sexuais, antes reprimidos pelas várias formas de discriminação, sinalizando certa vitória da luta dos movimentos sociais identitários e anti- homo fóbicos ${ }^{14}$.

$\mathrm{Na}$ tensão sobre essa influência da internet no comportamento sexual de juventudes, há outros autores ainda que vêem a mídia e o desenvolvimento

\footnotetext{
14 Sobre aglutinação de comunidades pornográficas na internet o autor Felipe Zago (2009) acredita que: "estamos diante da biossociabilidade: elege-se uma atribuição ou característica do corpo, algo que lhe é imanente ou que a ele esteja diretamente articulado para que em torno desta atribuição e em nome desta característica se construam laços, se produzam socializações entre os indivíduos. Esta sociabilidade, típica da contemporaneidade, é estruturada com fins políticos sensivelmente diferentes daqueles que outrora testemunhamos: os sujeitos se juntam em grupos pautados em características de seus corpos que thes são comuns com o objetivo de fazer valer suas corporeidades não mais como seres sociais, mas como seres individuais e singulares. Nas biossociabilidades não há um sentimento de pertencimento ao mundo, à sociedade, à cultura, mas sim um sentimento de pertencimento de um corpo, de uma singularidade única, de uma individualidade biocêntrica".
} 
tecnológico, em geral, como co-responsáveis pela circulação de outras formas de experienciar a sexualidade, e entre essas experiências estaria a construção de uma identidade sexual menos aprisionadora e mais híbrida (GUIMARÃES, 2008).

Ocorre ainda que ao investigar a temática da sexualidade no orkut, encontramos o mesmo número de comunidades tanto para gays quanto para lésbicas- 996, resultando num total de 1.992 comunidades virtuais. Em que pese o fato de ser similar o número de comunidades relacionadas ao tema gay e lésbica, verificamos, porém uma diferenciação elevada entre os títulos dessas comunidades.

O número de comunidades na chamada "gay(s)" que ironiza com a sexualidade homo afetiva, configurando chacotas e piadas preconceituosas é 95\% maior do que as comunidades com tal tendência, criadas sob a denominação lésbica(s).

Haveria que mais pesquisar, porém pela aplicação orkut, pode-se concluir genericamente que a homofobia contra o homem é muito mais explícita do que contra a mulher.

Vejamos o que diz o perfil "Renato Gay MLK Traveco" :

Quadro 3- Objetivos declarados do perfil "Renato Gay MLK traveco"

!!!MAIS QUI PORRA DE RENATINHO !!VC É FILHO DA PUTA FIKOU COM CONVERSINHA COM MINA DO OUTROS AGORA AGUENTA

quem sou eu: SOOU UMA BICHA LOKA , E Só ISSO..!!!!!!!!!, DOU O TOBAS MESMO!!!!!!!!!

Fonte: $\quad$ http://www.orkut.com.br/Main\#Profile?uid=1699019380346089250.

Pesquisa feita em 20 de julho de 2009.

Nossa pesquisa apontou também uma minoria de aglutinações virtuais articuladas com títulos e descrições tendenciosos à discriminação sexual e de gênero, apelos sexuais agressivos e apologias à abusos sexuais, apenas 
$3,1 \%$. Tal tendência confirma que a juventude tem muito pouca afeição à princípios sexuais intolerantes e discriminatórios, preferindo divulgar preceitos solidários e de ajuda à lutas em prol da cidadania sexual e/ou da sexualidade corporal.

Em consonância com a Declaração dos Direitos Sexuais quando esboça a sexualidade como uma parte integral da personalidade de todo ser humano e por isso deve ser respeitada, tal como os seres humanos, os jovens internautas, em suas afirmações públicas, conjugam muito mais com tendências humanitárias, bem como com as principais bandeiras por direitos sexuais, e apresentam baixíssimos índices de discriminações sexuais. Vale notar que hoje em dia, defende-se a idéia de que a sexualidade seja construída através da interação entre o indivíduo e as estruturas sociais, sendo essencial para o bem-estar individual, interpessoal e social (BUSSON; CASTRO; ABRAMOVAY, 2009).

As mensagens ligadas à saúde sexual física e/ou psicológica, educação sexual, prevenção e estudos científicos sobre sexualidade significaram 2,2\% das comunidades encontradas. Assim, fica claro que a sexualidade, entendida muitas vezes como fase biológica, com início na adolescência, não se confirma exatamente na forma em que é pensada pelos jovens internautas, pois apenas $2,2 \%$ das comunidades associam sexualidade à assuntos de saúde e/ou evolução biológica. Conforme o autor Michael Foucault, especialista em história da sexualidade, desejos sexuais não são entidades biológicas pré-existentes, mas constituídos no curso de práticas sociais determinadas historicamente (in BRAZ, 2006), e, a perspectiva jovem aqui analisada, em consonância com o autor, agrega muito pouco a idéia de faixa etária, corpo e sexualidade.

No entanto, um dado preocupante dessa estatística de apenas 2,2\% das comunidades serem ligadas à saúde sexual física e/ou psicológica, educação sexual e à prevenção sexual, diz respeito ao pouco interesse em se debater tópicos sobre prevenção e saúde de jovens sexualmente ativos, 
o que poderia indicar relativa despreocupação da juventude na possível aquisição de doenças sexuais, gravidez indesejada, etc, porém dados do PNDS (1996- 2005) ${ }^{15}$ evidenciam aumento do uso de preservativo entre jovens de 16 a 24 anos, de $19,5 \%$ para $55,5 \%$.

De certo que essa relativa incompatibilidade de registros (orkut/PNDS) prova que ainda que na esfera pública de debates sobre sexualidade os interesses mobilizatórios quanto à saúde e prevenção sexual sejam pequenos, na prática o índice de conscientização é crescente. Podemos destarte considerar algumas explicações como o fato de que apenas em meados dos anos 90 começam a surgir no Brasil os primeiros estudos de abrangência nacional sobre comportamento sexual e percepção de risco ao HIV (BERQUÓ; BARBOSA; LIMA, 2008), ou por outra, que os interesses relevantes para esfera pública civil não estão necessariamente atrelados ao nível alto ou baixo de conscientização dos sujeitos.

O termo de recorte (palavra-chave) "sexo" segue uma linha de raciocínio diferenciada em relação ao termo "sexualidade". Notamos que as comunidades virtuais que se intitulam ou descrevem com o termo "sexo" tendem mais à ironia, à cultos corporais, encontros sexuais e pornografias, do que as que se intitulam com o termo sexualidade. Segundo a classificação do Quadro 1, acima, 97,4\% das comunidades com a palavra "sexo" são descritas a partir de convite para relação sexual, fantasias sexuais, ironia à sexo de animais e situações sexuais, horóscopos eróticos, indicação de vídeos pornográficos, etc. Essa posição cognitiva e etimológica preponderante da palavra "sexo" se por um lado mostra-se conservadora corroborando com o juízo de que o lugar do sexo não é no campo dos direitos, da educação e da prevenção, por outro lado ao apelar para fantasias eróticas, indicação pornográfica e etc, foge do religiosamente conservador, pois não subordina o sexo à função meramente reprodutora,

\footnotetext{
${ }^{15}$ Sociedade Civil Bem-Estar Familiar no Brasil. Pesquisa Nacional sobre Demografia e Saúde 1996. Brasília; 1997.
} 
como preceitua a moral cristã. E, no Brasil é inegável que a questão da sexualidade sofreu grande influência católica e Estatal, onde:

\begin{abstract}
Já nos primeiros tempos coloniais a igreja considerava a sexualidade matéria de sua alçada, elevando à categoria do sagrado o sexo conjugal voltado para procriação e lançando tudo o mais no domínio diabólico. A partir do cristianismo a sexualidade passa a ser vista como pecado e apenas admitida no âmbito matrimonial e exclusivamente para a procriação. A copulação deveria servir só para dar a luz. (SILVA, 2008 p.11):
\end{abstract}

Já no recorte "sexualidade" apenas $21,9 \%$ das comunidades virtuais ligamse à pornografia e erotismo, a grande maioria, ou seja, 63,1 \% dizem respeito mesmo à busca por cidadania sexual.

Uma contradição observada em nossa investigação foi com relação às comunidades correspondentes ao tópico "aborto". Cerca de 85,6\% dessas comunidades são taxativamente e muitas vezes de forma ofensiva contra o aborto. De fato por mais que as estatísticas apontem que $63,1 \%$ das comunidades ligadas à temática "sexualidade" se orientam por discutir direitos, liberdade e contra exploração sexual, esses direitos e liberdades especificamente nas comunidades que discutem o aborto, são ventilados sobre parâmetros tradicionalistas e até preconceituosos, como se observa na seguinte descrição da comunidade virtual "Não ao aborto, sou contra" :

Quadro 4- Objetivos declarados da comunidade "Não ao aborto, sou contra" (306 membros) 
Comunidade aonde espero como médico desencorajar com o que escrevo a todas as pessoas que possam querer fazer essa pratica... Relato que é abortar... Inicia-se o terceiro mês.. Meus filhos foram mortos nesta faixa de idade... Nesta época tranqüilos, felizes.. Brincando... Talvez tentando exprimir a felicidade que irão trazer.. Agradecendo chance a de $\quad$ viver.. Então a mãe foi a Clínica de Abortamento.. Decidida a acabar com algo que não lhe pertence pois a vida de um ser humano é algo divino.. Primeiramente foi sedada, dopada, drogada para nada sentir..Depois o medico que se prostitui.. Dilata o colo uterino e coloca um tubo dentro do ventre materno.. Os pequenos bebezinhos então fogem desesperados.. E o sugador pega meu filho. E é arrancado por sucção um membro.. Pode-se ver um ser humano completo agonizar de dor.. Sem entender Sem saber o porquê deles estarem sendo mortos.. Esquartejados. Sem entender talvez pensem: Mamãe porque está matando a gente? O Abdômen então é dilacerado e logo estão mortos.

Fonte:

http://www.orkut.com.br/Main\#Community?cmm=16601589.

Pesquisa feita 10 e 11 de maio de 2008

Dado ainda curioso nessa querela é que das 12 palavras-chave que pesquisamos, a segunda chamada que apresenta maior número de comunidades é a "aborto", com 786 comunidades, 17\% em relação às demais, segundo o Gráfico 1 a seguir. Deste modo, supõem-se que pelas palavras-chave aqui propostas um dos assuntos mais discutidos é o aborto, com uma enorme taxa de $85,6 \%$ de comunidades que o rejeitam.

Gráfico 1 - Porcentagem dos temas ligados à sexualidade nas comunidades virtuais no orkut 


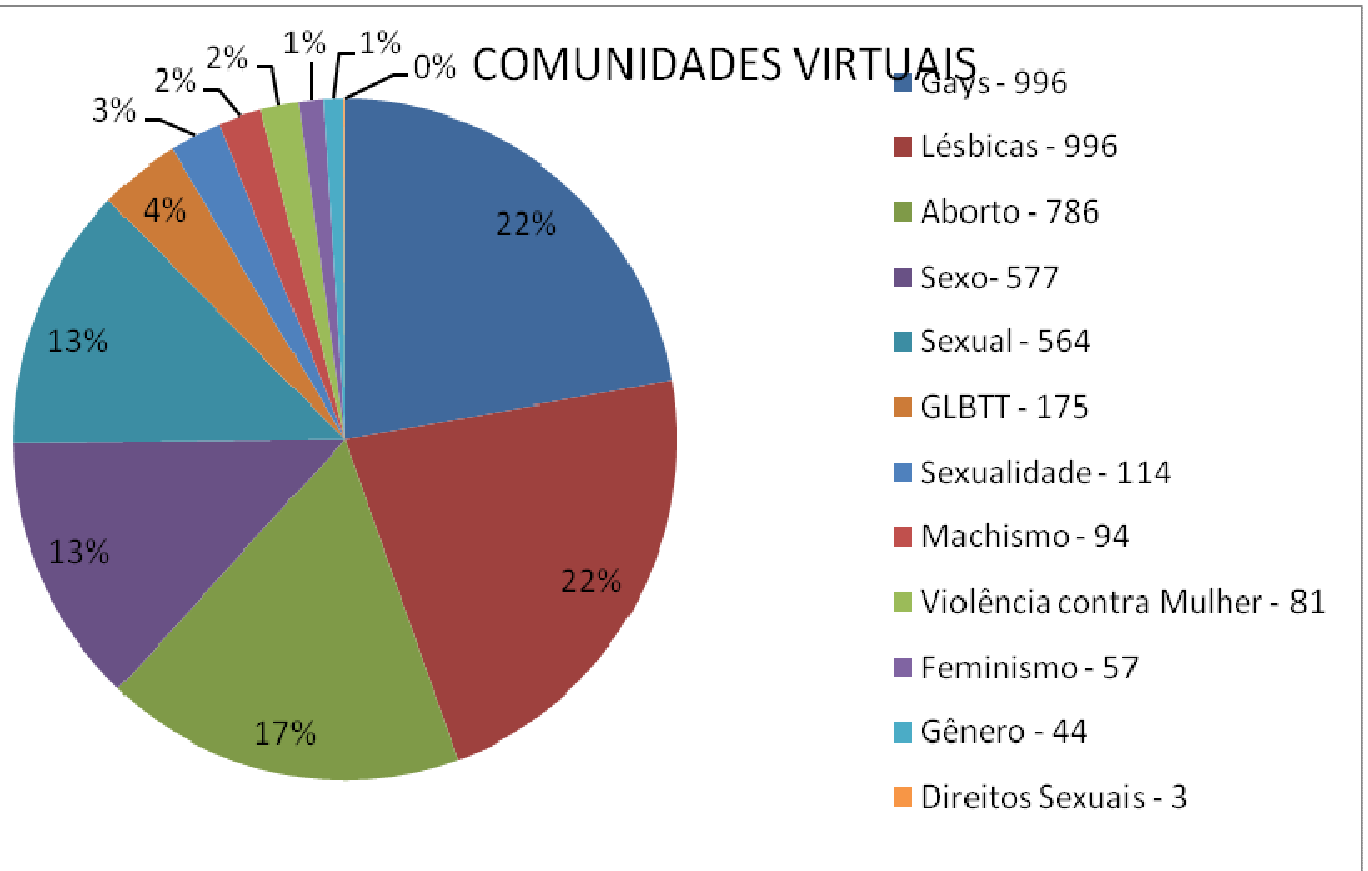

Fonte: Levantamento no www.orkut.com dias 10 e 11 de maio de 2008 e 27 de junho de 2009

Note-se no Gráfico 1 que a palavra recorte denominada "direitos sexuais" congrega poucas comunidades, com tal chamada encontramos apenas 3 comunidades. Apesar de considerarmos que os temas discutidos nas comunidades em boa parte relacionarem-se a aspectos dos direitos sexuais, entre os internautas há uma procura por comunidades com títulos mais específicos, menos genéricos, tais como machismo, feminismo, violência contra mulher etc. Ou seja, os debates sobre sexualidade não parecem decolar de direitos sexuais em geral, e sim de parâmetros específicos de análise desses direitos.

Por ora podemos compreender, a partir de nossa pesquisa, disposta em anexo, que em todas as descrições das 4.487 comunidades não foi detectada nenhuma comunidade com traços ou títulos referentes especificamente ao que chamaríamos "dialética do prazer" (DURO, 1980) que sugere o entrelace entre prazer para si e para o outro/a, explorando 
possibilidades, descobertas e criatividade na sexualidade juntos/as. Ao contrário de um prazer dialético, o que se confirma é que na maioria das comunidades predomina a idéia de um prazer buscado unilateralmente, independentemente da relação social ou afetiva. A nossa interpretação remete à interlocução sexo consumo, sexo tecnologia. Vejamos a descrição da comunidade "Sexo virtual só com história":

Quadro 5-_Objetivos declarados da comunidade "Sexo virtual só com história" (625 membros)

Uma comunidade para aquelas pessoas que são virtualmente promíscuas(os) mas que na realidade são fiéis aos seus(suas) esposos(as)... Mas internet não é traição...

Aqui a excitação e as fantasias falam mais alto, mas não tem espaço para jogos e propagandas

\section{Qualquer opinião sobre a comunidade, deixem nesse tópico aqui:}

Fonte: http://www.orkut.com.br/Main\#Community?cmm=943998. Pesquisa feita 10 e 11 de maio de 2008.

Numa outra comunidade sobre "sexo", ao invés da descrição buscamos os tópicos das discussões internas - ver Quadro 5

\section{Quadro 6- Tópicos de Discussão da Comunidade "Sexo, tesão e prazer STP” (10.028 membros)-, considerando número de mensagens postadas:}

- Quando o instinto fala mais alto ...10

- Porque dizer eu te amo é complicado ? 29

- Manual da putinha... 1

- Relato das mulheres que já utilizaram serviço de garotos de programa...4

- Aventuras no swuing 15

- Xupadoras de saco ...4

- Metrosexual, frescura ou modernidade...24

- Raspadinha ...39

- Sexo a três ...32

- Confesso que sou safado ...28

- Pica dos famosos 
Fonte:

http://www.orkut.com.br/Main\#Community?cmm=93467101.

Pesquisa em 10 e 11 de maio de 2008.

De fato a chamada "dialética do prazer" não apresentou nenhuma comunidade, o que sugere que os jovens têm alcançado o prazer sexual não exatamente na dialética e no compartilhamento, mas sim de diversas formas, e que cada um encontra a sua, seja com putinhas, com xupadoras, com safados, travestis, a três, enfim.

Numa ulterior perspectiva de observação, vimos uso subversivo constante da norma culta da língua encontrado na sociabilidade on line. Para BRAGA (2008) esse cenário indica que a introdução da tecnologia também tem provocado a criação/divulgação de uma nova cultura de identidades, sejam elas sexuais, sociais ou políticas. $\mathrm{Na}$ internet é visível um repertório público terminológico distinto que acaba influenciando e reorganizando as diferentes formas de ver o mundo e conseqüentemente de reivindicar cidadanias.

São diversos perfis de internautas que interagem num mesmo espaço e sobre a mesma chamada comunitária virtual, mas com experiências regionais diferenciadas, o que faz diferir da vida real, quando se tem limitações de espaço e tempo. Um internauta de Salvador, por exemplo, de qualquer idade, cor, religião, caráter, profissão e sexo tem a liberdade de sociabilizar em qualquer comunidade virtual, de diversas e quaisquer regiões. Desse jeito existirá um acúmulo de experiências pluriculturais que pensando politicamente trará para a esfera pública o máximo de democracia possível, pois tem a capacidade de aglomerar diferenças de todo tipo, criando um "quadro comum de significados" (STREET; SCOTT, 2000, p.233).

Para alguns estudiosos, a nova política, ou a "nova cultura política" se manifesta também com práticas que promovem a inversão da imagem 
convencional de celebridades, marcas ou coisas do gênero, funcionando como a criação de verdadeiras "embalagens políticas", permissíveis de serem divulgadas mais constantemente pela internet, já que a televisão e o rádio têm todo um escopo de seriedade, e/ou no mínimo um compromisso com a fonte das notícias e imagens. (CLARK, HOFFMAN- MARTINOT 1998, MARSHALL 1997, FRANKLIN 1994, SCAMMELL 1995 apud SCOTT; STREET, 2000). Campanhas na rede virtual nascem muitas vezes descentralizadas e desprogramadas, sem clareza sobre suas metas ou coligações, mas podem ter impacto imensamente negativo sobre marcas, produtos, empresas e governos; é o caso da uma rede de ONGs que lançaram uma bem sucedida campanha através da rotulagem da própria empresa Monsanto contra a produção de sementes geneticamente estéreis, o que gerou efeitos positivos off lines. (BENNETT, 2003)

A incorporação de diferentes atores à esfera pública a partir da sociabilidade virtual tem uma maneira que radicaliza ainda mais a participação popular, quando demonstra a emergência de novos sujeitos "enunciadores" (BRAGA, 2008), ou seja, aqueles que antes da internet eram meros receptores de informações produzidas por rádio e televisão, agora se colocam no domínio da criação e interação de notícias e ideologias, construindo e consumindo culturas, identidades e "desidentificações".

Em outra comunidade, com um número pequeno de filiados, denominada "Sexualidade e luta de classes", se avança no discurso político da sexualidade, seus nexos com a economia política, recusando o contrato heterossexual como hegemônico e denunciando violências relacionadas à homofobia. Vejamos a descrição da comunidade:

Quadro 7- Objetivos declarados da comunidade: "Sexualidade e luta de classes" (344 membros): 
"Pessoas se viram quando vêem um homem beijando outro homem, mas não se chocam quando vêem milhares morrendo de fome."

Você conhece algum gay pobre que não é perseguido? Quantos travestis da periferia a polícia mata por ano? O que acontece com um homossexual que mora numa favela dominada por violência policial?

A homofobia e o machismo não estão desvinculados da sociedade de classes, baseada na banalização sexual, na instituição monogâmica, que é uma das bases do Estado, da ALIENAÇÃO DO CONSUMO, da escravidão, submissão da mulher, do preconceito, racismo e da repressão sexual(NEUROZES, FACISMOS E CATOLICISMOS). Uma das causas e conseqüências da opressão do proletariado, de sua desunião, de sua exploração a este sistema mercantil que mantém a ditadura da propriedade, do Capital e da autoridade.

Fonte: $\quad$ http://www.orkut.com.br/Main\#Community.aspx?cmm=48917329. Pesquisa em 10 e 11 de maio de 2008.

É difícil dizer mais sobre os significados do processo de interpretação das comunidades virtuais, principalmente porque milhares são marcadas pela quase ausência de debates. Existe mais a preocupação em estar filiado à comunidade do que propriamente defender interesses e opiniões. Independente do número de participantes, as comunidades podem se mostrar esvaziadas de debates; há comunidades com até 103 mil participantes e com mais de 3 anos de existência que nunca demonstrou discutir absolutamente nada. Isso indica que os jovens internautas brasileiros procuram muito mais um sentido de pertença, uma representação simbólica de seus ideais, uma possível busca e curiosidade sobre um tema, que propriamente trocas e diálogos sobre os mesmos. $\mathrm{Na}$ grande maioria dos casos é como se houvesse mais aspiração de filiação às bandeiras e lemas, do que de discussão, de trocas, de exposição, de diálogo e de participação social, numa tentativa de somente sustentar aspirações e representar-se.

Sobre representação social a interpretação é de que é uma forma de saber que tem com o seu objeto uma relação de simbolização (substituindo-o) e de interpretação (conferindo-lhe significações): 
[...] a representação é uma construção e uma expressão do sujeito. Esta atividade pode remeter a processos cognitivos. Mas a particularidade do estudo das representações sociais é o fato de integrar na análise desses processos a pertença e a participação sociais ou culturais, do sujeito. Por outro lado ela também pode relacionar-se à atividade mental de um grupo ou de uma coletividade ou considerar essa atividade como o efeito de processos ideológicos que atravessam os indivíduos. (JODELET, 2001, p. 27)

A filiação a uma comunidade virtual sugeriria busca de pertencimento, um envolvimento de sentidos, mas não necessariamente a defesa de sentidos práticos ou mesmo a concretização de idéias para além de suas explicitações. De toda forma não se pode negar que há a partilha, ainda que simbólica, de uma condição social que "é acompanhada de uma relação com o mundo, valores, modelos de vida" (JODELET, 2001, p 29). Segundo a autora, as representações sociais são compreendidas como funcionais na manutenção de identidades. Destarte, a ausência e/ou o pouco debate dentro das comunidades virtuais não significariam obrigatoriamente a carência de idéias sobre sexualidade, pois afinal os sujeitos escolhem as comunidades e inserem-se nelas, afirmando e buscando ora identidades políticas, pornográficas, preconceituosas ou de saúde sexual, ora a emancipação de proposições e direitos.

Vem à tona novamente a noção de internet enquanto espaço público, pois muitos entendem que os espaços públicos seriam aquelas instâncias deliberativas que permitem o reconhecimento e dão voz a novos atores e temas (DAGNINO; OLIVEIRA; PANFICHI, 2006, p.26). No entanto, no caso específico em que estudamos, qual seja, o orkut, confiamos numa dimensão, citada pelo próprio Habermas, que considera o espaço público como interface indireta entre Estado e sociedade, sem potencial para incidir efetivamente, mas com ilimitada capacidade de influenciar, denunciar abusos e assim frear o poder hegemônico do Estado, da cultura moralista e do mercado. 
Segundo intérpretes do autor Jürgen Habermas a "ação comunicativa" é plenamente sediciosa, pois está sempre a mobilizar recursos para combater a "ação instrumental".

Para Habermas (1981) a "ação instrumental" é a reprodução de todos os conflitos e dissensos em mercadoria, é uma ação orientada para o êxito da sua própria reprodução que tende a neutralizar os conflitos, pois vê os sujeitos como meros objetos, subordinados à cálculos, à interpretações impessoais, e não como seres dotados de opiniões e concepções de mundo.

De outro lado está a "ação comunicativa" que se caracteriza por estruturas comunicativas que combatem e/ou direcionam o sistema político, em menor ou maior grau, proporcionalmente ao seu volume.

A questão suscitada pode ser descrita da seguinte forma:

\begin{abstract}
Esses processos de resistência se organizam no mais das vezes de maneira informal, por meio de redes de comunicação, de discussão e de ação que têm por objetivo barrar a interferência instrumental em formas de vidas estabelecidas. [...] como, por exemplo, quando um movimento contra a construção de uma usina hidrelétrica apresenta um parecer técnico contrário àquele que justificaria essa construção, com o objetivo de interrompê-la. Trata-se de voltar à lógica instrumental contra ela mesma, com a inspiração comunicativa de revelar a parcialidade da razão instrumental e a necessidade da inclusão de outras vozes no processo. (NOBRE; TERRA, 2008, p.23)
\end{abstract}

A ação comunicativa para Habermas é crucial à política, é o que the dá legitimidade e permite a constante regeneração da administração parlamentar. Assim, quanto mais ativa for a esfera pública e seus fluxos comunicativos, maiores chances de atingir e influir no centro da decisão política.

Para que as decisões políticas sejam tomadas diretamente via web, seria necessário transpor as redes periféricas da esfera pública para redes institucionalizadas desta mesma, é nesse sentido que é preciso uma instância que pertença ao sistema sem se encontrar encapsulada nele e por ele (NOBRE; TERRA, 2008, p.27), e para Habermas o Direito é essa 
instância que media o sistema e o mundo da vida, através do "procedimento"16.

Em função de sua operacionalidade técnica descentralizada e autoorganizante, o orkut abaliza-se numa estrutura radicalmente democrática, mas ao mesmo tempo também caótica para possíveis tomadas de decisões, pois contém diversas falhas para identificação exata do usuário, admitindo a invenção de fakes ${ }^{17} \mathrm{e}$, portanto uma inconsistência numérica e analítica dos debates $^{18}$.

Existem muitas experiências de grupos virtuais que articulam ações e definem propostas pelo orkut, mas, cremos essa relação não pode ser levada como referência para decisões mais globais do tipo Estado e sociedade civil.

Valeria também explorar mais a comunicação ou a "incomunicação" via internet para delimitar formas de expressão sobre temas ligados a sexualidade. O exercício que fizemos é ainda embrionário, mas sugere a diversidade de formatações do tema, suas representações e o acento preconceituoso e estereotipado que em muitos casos essas assumem.

Não se tratou aqui de dissolver qualquer rol de direitos sexuais nem de invalidar o esforço de enumerá-los mais concretamente; objetivou-se sim compreender a internet enquanto via pela qual esses direitos são discutidos e aprofundados, o que se traduz na idéia de uma democratização dos direitos sexuais.

\footnotetext{
${ }^{16}$ Traduzindo Habermas, NOBRE e TERRA (2008) mencionam que o procedimento "é a forma pela qual os processos de formação da opinião e da vontade dos cidadãos têm de ser institucionalizados, de forma a que, a cada vez , a maior participação possível possa ser garantida. Para que isso possa ocorrer a lógica procedimental deve prevalecer de tal maneira que sejam institucionalizadas as formas de discussão, de participação e de deliberação que permitam o surgimento do maior número possível de vozes, de tematizações, de valores e de interesses".

${ }^{17}$ Pessoas com identidades falsas.

${ }^{18}$ A pesquisa no orkut provou que nessa aplicação virtual há muitas peculiaridades como: indefinição de identidade de pessoas, possibilidade de uma pessoa estar em milhares de comunidades ao mesmo tempo, criação de fakes, dinâmica de idéias que ora estão lá e ora desaparecem, etc.
} 
Ao resgatar alguns modos e quantidades pelas quais a juventude tem discutido os direitos sexuais no orkut, depara-se fundamentalmente com um comportamento de massas assinalado, podemos dizer assim, por uma catarse de exasperações, que incompatibiliza, de modo peculiar, o projeto hegemônico da democracia participativa. A idéia da limitação da participação do cidadão a momentos de sufrágio universal hoje em dia só deve ser aceita se estivermos de acordo com o conceito de participação ligado diretamente à deliberação política, e nem assim, pois hoje há uma abertura a partir da participação de Conselhos, Fóruns e ONGs no governo. Mas se pensarmos como Habermas, no arranjo das "ações comunicativas" e dos futuros "procedimentos" institucionais, temos que a internet além de ampliar a democracia por apontar fatores como os acima citados (diversidade de sujeitos, ilimitados temas, acesso fácil e gratuito a quaisquer questões políticas, informalidade, publicidade de denúncias, descentralização do poder de informação, etc), também fere o princípio do "elitismo democrático" (VITALE; MELO, 2008) que anuncia a impossibilidade de acordo coerente entre indivíduos e política devido à irracionalidade das massas.

O orkut demonstrou que mesmo no senso comum, na informalidade e diante de ausentes propostas politicamente educativas de governos ou da empresa que dispõem do programa virtual, os cidadãos conseguem se engajar e realizar seus anseios por participar e compartilhar ativamente da vida coletiva e dos processos políticos. $\mathrm{Na}$ imensa seara de argumentos públicos dos jovens, oportunizados pela internet, muito há que se considerar posto que são válidas precisamente aquelas normas de ação às quais todos os possíveis concernidos poderiam dar o seu assentimento, na qualidade de participantes de discursos racionais (HABERMAS, apud VITALE; MELO, 2008, p. 229). 
deliberações institucionalizadas e opiniões públicas que se formaram de modo informal

(Idem, 2008, p. 243)

Finalmente, ainda que muitos estudos sobre a participação política dos jovens pela internet já nos esteja dando respostas satisfatórias, devemos lembrar que a configuração técnica da rede permite atualizações muito rápidas, sendo importante que se tenha em vista que essas práticas e suas concepções são, em breve análise, muito dinâmicas. Há uma atualização constante de agrupamentos e discussões virtuais que, ainda que muitas vezes fugazes, sem dúvida têm representado um peso de forças contrárias circunstanciadas segundo novas condições de embate. Exemplos de novidades políticas não faltam: jovens que nunca circularam em ambientes políticos, ou nunca defenderam diretamente causas sociais hoje se encontram muito mais propensos, e acabam fundando uma concepção de militância quase que completamente inversa ao sentido tradicional da palavra.

Enfim, a capacidade de aglomeração de indivíduos que outrora se encontravam dispersos ou isolados ajuda a compreender ou reinterpretar os desafios organizacionais políticos de nossa época.

\section{Referências}

BENNETT, W. Lance. Communicating Global Activism. Strengths and vulnerabilities of networked politics. Information, Communication \& Society. Londres. 6:2 2003.

BERQUÓ, Elza; BARBOSA, Regina Maria; LIMA, Liliam Pereira de . Uso do preservativo: tendências entre 1998 e 2005 na população brasileira. Rev. Saúde Pública, Jun 2008, vol.42, suppl.1, p.34-44. ISSN 0034-8910

BOGO, Kellen Cristina. A História da Internet - Como Tudo Começou.

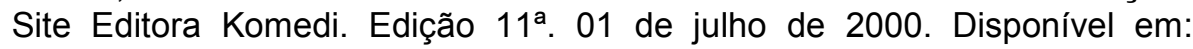
<http://kplus.cosmo.com.br/materia.asp?co=11\&rv=Vivencia >

Acessado em: 20 de julho de 2009

BRAZ, Camilo de Albuquerque. Macho versus Macho: a produção discursiva da hiper-masculinidade em alguns contextos homoeróticos na cidade de São Paulo., UNICAMP 2006. 
BRAGA, Adriana. Personas Materno- Eletrônicas: feminilidade e interação no blog mothern. Porto Alegre: Sulina, 2008

BUSSON, Shayana; CASTRO, Mary Garcia; ABRAMOVAY, Mirian. Enlaçando Gênero e Sexualidades, Focalizando Jovens. Anais do Seminário Internacional Enlaçando Sexualidades. Salvador- Bahia, 2009. Disponível em: $<$ http://www.miriamabramovay.com/site/index.php?option=com content\&vie $\mathrm{w}=$ section\&layout=blog\&id=8\&ltemid=9> Acessado em: 12 de dezembro de 2009

CARRANO, Paulo; BRENNER, Ana Karina. Formas e conteúdos da participação de jovens na vida pública. Observatório Jovem: Rio de Janeiro. $2008 . \quad$ Disponível em: $<$ http://www.uff.br/obsjovem/mambo/index.php?option=com content\&task=vi ew\&id=541\&ltemid=23> Acessado em: 10 de março de 2009

CASTELLS, Manuel. O poder da Identidade. Tradução: Klauss Brandini Gerhardt. Ed. Paz e Terra S/A. Rio de Janeiro:1999.

CORREAA, Sonia. Cruzando a linha vermelha: questões não resolvidas no debate sobre direitos sexuais. Horizontes Antropológicos., Dez 2006, vol.12, no.26, p.101-121. ISSN 0104-7183. Disponível em: <http://www.scielo.br/pdf/ha/v12n26/a05v1226.pdf> Acessado em: 2 de julho de 2009.

DAGNINO, Evelina (org). Sociedade Civil e Espaços Públicos no Brasil. São Paulo: Paz e Terra, 2002.

; OLIVEIRA, A.; PANFICHI, A. (orgs.). 2006. A disputa pela construção democrática na América Latina. São Paulo: Paz e Terra.

DECLARAÇÃO DOS DIREITOS SEXUAIS - Disponível em: $<$ http://www.ibiss.com.br/dsex destaque.html> Acessado em: 20 de julho de 2009

DURO, Enrique Gonzales. A dialética do prazer. In Encontro com a civilização brasileira. Rio de Janeiro. Civilização Brasileira, maio de 1980, n 23.

GOMES, Wilson. A Democracia Digital e o Problema da Participação Civil na Decisão Política. Revista Fronteiras- estudos midiáticos. Vol II, set/dez. Rio Grande do Sul. 2005. P.214-222.

GUIMARÃES, Thayse Figueira. Narrativas de experiências sexuais em torno da internet: a construção do gênero e da sexualidade em uma "Lan House". Fazendo Gênero 8 - Corpo, Violência e Poder. Florianópolis 2008.

Disponível

em: 
$<$ http://www.fazendogenero8.ufsc.br/sts/ST56/Thayse Figueira Guimaraes 56.pdf>

Acessado em: 20 de julho de 2009.

HABERMAS, Jürgen. Theorie des kommunikativen Handelns, Frankfurt: Suhrkamp.1981

INSTITUTO BRASILEIRO DE GEOGRAFIA ESTATÍSTICA. Disponível em : $<$ http://www.ibge.gov.br/home/estatistica/populacao/acessoainternet/default. shtm> Acessado em: 10 de março de 2008

JODELET, Denise (org). As Representações Sociais. Rio de Janeiro, Ed UERJ 2001

MARQUES, Francisco Paulo Jamil Almeida. Debates políticos na Internet: a perspectiva da conversação civil. Opin publica, maio 2006, vol.12, no.1, p.164-187. ISSN 0104-6276

MUNIZ. Diógenes.Microsoft faz campanha contra o Orkut. Folha Online. 9 de Janeiro de 2008. Acessado em: 16 de novembro de 2008.

NOBRE, Marcos; TERRA, Ricardo (Org.) Direito e democracia: um guia de leitura de Habermas. São Paulo: Malheiros, 2008

RUIZ, Eva Espinar; RíO, Maria José González. Jóvenes conectados. Las experiencias

de los jóvenes con las nuevas tecnologias. Universidade de Alicante Espanha. Revista 9. 2008. Disponivel em: <http://www.fesweb.org/publicaciones/res/archivos/res09/06.pdf> Acessado em: 30 de janeiro de 2009

SILVA, José Amilton da. O olhar das religiões sobre a sexualidade. 2008. Site Dia de Educação- Governo do Paraná. Disponível em: $<$ http://www.diaadiaeducacao.pr.gov.br/portals/pde/arquivos/728-4.pdf> Acessado em: 20 de julho de 2009

SITE BOA SAÚDE SAÚDE. Disponível em: <http://boasaude.uol.com.br/Lib/ShowDoc.cfm?LibDoclD=3994\&ReturnCatl $\mathrm{D}=1784$ > Acessado em: 20 de agosto de 2009

SITE ORKUT - INTERNETNETWORK. Disponível em: <http://www. orkut.com>

SORJ. Bernardo. Internet, espaço público e marketing político: entre a promoção da comunicação e o solipsismo moralista. Rev. Novos Estudos. 2006

Disponível em: <http://www.bernardosori.com/pdf/wp2 portugues.pdf> Acessado em: 15 de abril de 2007. 
STREET, John; SCOTT, Alan. From Media Politics to E-protest: The use of popular culture and new media in parties and social movements. Information, Communication \& Society. Londres. Vol 3, June 2000 , pag 215 $-240.2000$.

ZAGO, Luis Felipe. Um oásis erótico? Internet, masculinidade e homossexualidade. CiudadaniaSX 2009. Disponível em: $<$ http://www.ciudadaniasx.org/content/view/1040/125/>. Acessado em: $20 \mathrm{de}$ agosto de 2009

VAZ, José Carlos. Uso da Internet pelos governos e promoção da cidadania. Rev Unicsul, dez 2003, vol 8, n 10, p54-65. ISSN 1414-1892.

VITALE, Denise; MELO, Rúrion Soares. Política Deliberativa e o modelo procedimental de democracia. In NOBRE, Marcos; TERRA, Ricardo. Direito e Democracia Um guia de leitura de Habermas. São Paulo: Malheiros Editores. 2008. 